\title{
GROWTH PLATE EXTRACELLULAR MATRIX-DERIVED SCAFFOLDS FOR LARGE BONE DEFECT HEALING
}

\author{
G.M. Cunniffe ${ }^{1,2,3}$, P.J. Díaz-Payno ${ }^{1,2,3}$, J.S. Ramey', O.R. Mahon ${ }^{4}$, A. Dunne ${ }^{4}$, E.M. Thompson ${ }^{3,5}$, F.J. O’Brien ${ }^{1,2,3,5}$ \\ and D.J. Kelly ${ }^{1,2,3,5 *}$
}

\begin{abstract}
${ }^{1}$ Trinity Centre for Bioengineering, Trinity Biomedical Sciences Institute, Trinity College Dublin, Dublin, Ireland.
${ }^{2}$ Department of Mechanical and Manufacturing Engineering, School of Engineering, Trinity College Dublin, Dublin, Ireland.

${ }^{3}$ Advanced Materials and Bioengineering Research Centre (AMBER), Royal College of Surgeons in Ireland and Trinity College Dublin, Dublin, Ireland.

${ }^{4}$ Molecular Immunology Group, School of Biochemistry and Immunology, Trinity College Dublin, Dublin, Ireland.

${ }^{5}$ Tissue Engineering Research Group, Department of Anatomy, Royal College of Surgeons in Ireland,

123 St. Stephen's Green, Dublin 2, Ireland
\end{abstract}

\begin{abstract}
Limitations associated with demineralised bone matrix and other grafting materials have motivated the development of alternative strategies to enhance the repair of large bone defects. The growth plate (GP) of developing limbs contain a plethora of growth factors and matrix cues which contribute to long bone growth, suggesting that biomaterials derived from its extracellular matrix (ECM) may be uniquely suited to promoting bone regeneration. The goal of this study was to generate porous scaffolds from decellularised GP ECM and to evaluate their ability to enhance host mediated bone regeneration following their implantation into critically-sized rat cranial defects. The scaffolds were first assessed by culturing with primary human macrophages, which demonstrated that decellularisation resulted in reduced IL- $1 \beta$ and IL- 8 production. In vitro, GP derived scaffolds were found capable of supporting osteogenesis of mesenchymal stem cells via either an intramembranous or an endochondral pathway, demonstrating the intrinsic osteoinductivity of the biomaterial. Furthermore, upon implantation into cranial defects, GP derived scaffolds were observed to accelerate vessel in-growth, mineralisation and de novo bone formation. These results support the use of decellularised GP ECM as a scaffold for large bone defect regeneration.
\end{abstract}

Keywords: Growth plate, Extracellular matrix, Scaffold, Large bone defect regeneration, Scaffold immune response.

*Address for correspondence:

Prof. Daniel Kelly

Trinity Centre for Bioengineering,

Trinity Biomedical Sciences Institute,

152-160 Pearse Street, Dublin 2, Ireland

Telephone: +353-1-8963947

E-mail: kellyd9@tcd.ie

\section{Introduction}

The repair of large bone defects still presents a significant clinical challenge, with the use of autografting material remaining the gold standard treatment despite the drawbacks associated with this approach (Dimitriou et al., 2011). Biological scaffolds derived from animal and human extracellular matrix (ECM), which are composed of instructive structural and functional molecules to facilitate tissue regeneration, have been successfully used clinically to repair numerous different tissues and organs (Benders et al., 2013). Demineralised bone matrix is commonly used in bone regeneration (Gruskin et al., 2012; Solheim, 1998), although concerns remain as to its osteoinductivity (Aghdasi et al., 2013; An et al., 1995; Tilkeridis et al., 2014). Long bones form by the coordinated process of endochondral ossification, with the postnatal growth and development of our limbs driven by the growth plates (also called the epiphyseal plates). The growth plate (GP) is known to contain members of the transforming growth factor (TGF)- $\beta$ family, including bone morphogenetic protein (BMP), as well as vascular endothelial growth factor (VEGF) and Indian hedgehog (Ihh), which are known to be strongly osteoinductive (Alini et al., 1992; Anderson et al., 2000; Carlevaro et al., 2000; Gerber et al., 1999; Kronenberg, 2003; Nilsson et al., 2007; Qiu et al., 2015; Wang et al., 2004). Indeed, powdered demineralised GP has been shown to be osteoinductive in vivo, supporting the development of a bone ossicle following ectopic implantation into rats (Bigham et al., 2011). Clearly, such ECM derived biomaterials have tremendous potential for bone regeneration; however, realising this potential requires processing them into biological scaffolds capable of facilitating vascularisation and host osteo-progenitor mediated bone formation.

The ideal scaffold for bone regeneration is biocompatible, allows for cell infiltration and provides instructive cues to infiltrating cells, preferably to induce an osteogenic response. Porous scaffolds produced using collagen and hydroxyapatite, the two main constituents of bone, have been shown to encourage osteogenesis of MSCs in vitro and can support bone regeneration in vivo (Calabrese et al., 2016; Chen et al., 2015; Cunniffe et al., 2010; Cunniffe and O'Brien, 2011; David et al., 2015; Gleeson et al., 
2010; Prosecka et al., 2015; Villa et al., 2015). Ideally scaffolds have an open interconnected pore structure, with pore sizes in the range of 85-325 $\mu \mathrm{m}$ best supporting osteogenesis (Karageorgiou and Kaplan, 2005; Murphy et al., 2010; O'Brien et al., 2007). The osteoinductivity of these scaffolds can be improved by the incorporation of gene and growth factors such as BMP-2 and VEGF (Quinlan et al., 2015a; Quinlan et al., 2015b; Samorezov and Alsberg, 2015), although it remains uncertain as to what is the ideal combination of matrix components and growth factors to safely induce osteogenesis without the need for excessive levels of growth factors.

Rather than building a bone mimetic scaffold from the bottom-up using collagen and mineral components found in bone, and then systematically incorporating growth factors into such a construct, the goal of this study was instead to produce a porous osteoinductive scaffold from decellularised growth plate, the precursor matrix of long bones. Native and in vitro cell culture derived ECMs are commonly used to produce scaffolds for tissue engineering (Almeida et al., 2014; Cunniffe et al., 2015; Jin et al., 2007; Kheir et al., 2011; Kim et al., 2015; Lau et al., 2012; Lu et al., 2011; Pati et al., 2015; Pattabhi et al., 2014; Sutherland et al., 2015); however, the ideal matrix to facilitate bone regeneration has yet to be established. As previously stated, the GP matrix contains many important growth factors for inducing bone growth which render it as an attractive option for generating an osteoinductive ECM derived scaffold. The hypothesis of this study is that a decellularised GP ECM derived scaffold will support vascularisation and accelerated bone formation following implantation into critically-sized defects. The first objective of the study was to decellularise GP ECM and to use this biomaterial to produce a porous scaffold. We next evaluated the osteoinductivity of this scaffold in vitro by assessing its capacity to promote osteogenesis of MSCs via either an intramembranous or an endochondral pathway. The final phase of the study assessed the capacity of these scaffolds to support healing of critically-sized rat cranial defects.

\section{Materials and Methods}

\section{Decellularisation and scaffold fabrication}

Growth plate (GP) tissue was harvested from the femur and tibia of porcine hind limbs (3-4 months old) shortly after sacrifice. The GP region was reached by sawing the bone through the long axis, and breaking the bone open along the softer GP region, allowing the GP tissue to be scraped out in small pieces using a scalpel $\left(\sim 1 \mathrm{~mm}^{3}\right)$. These small pieces were then minced in distilled $\mathrm{H}_{2} 0$ using a homogeniser (IKAT10, IKA ${ }^{\circledR}$ Works Inc., NC, USA) to create an ECM slurry. The effect of decellularisation was evaluated, comparing native GP (no additional treatment prior to freeze-drying), to a detergent-based technique using $0.1 \%$ sodium dodecyl sulphate (SDS; Sigma-Aldrich); following comparisons with other detergents commonly used for decellularisation (Cheng et al., 2014; Gilbert et al., 2006; Luo et al., 2016; Luo et al., 2015), results not shown. Decellularised GP slurry underwent two freeze-thaw cycles in a hypotonic buffer $(10 \mathrm{mM}$ Trizma hydrochloride and $5 \mathrm{mM}$ ethylenediaminetetraacetic acid (EDTA) at $\mathrm{pH}$ 7.4), washed in saline (PBS), and treated for $1 \mathrm{~h}$ at room temperature in $0.1 \%$ SDS. Following subsequent PBS washes, the slurry was placed in a DNase/RNase solution $(5 \mathrm{mM} \mathrm{MgCl}, 10 \mathrm{U} / \mathrm{mL}$ of DNase, and $10 \mathrm{U} /$ $\mathrm{mL}$ of RNase) and incubated for $1 \mathrm{~h}$ at $37^{\circ} \mathrm{C}$. Following this initial evaluation, all succeeding GP scaffolds used in the in vitro and in vivo studies were decellularised using this method.

The homogenised tissues (native GP, or decellularised GP) were centrifuged and the supernatant was removed. The remaining material was re-suspended in distilled $\mathrm{H}_{2} \mathrm{O}$ at a concentration of $500 \mathrm{mg} / \mathrm{mL}$. The slurry was transferred to custom-made specific polydimethylsiloxane (PDMS) cylindrical moulds (resulting in constructs of $5 \mathrm{~mm} \times 3 \mathrm{~mm}$ for in vitro, and $7 \mathrm{~mm} \times 2 \mathrm{~mm}$ for in vivo studies) and freeze-dried (Triad, Labconco, KC, USA) to produce porous scaffolds. Briefly, the slurry temperature was reduced to $-30{ }^{\circ} \mathrm{C}\left(1{ }^{\circ} \mathrm{C} / \mathrm{min}\right)$ and maintained for $1 \mathrm{~h}$ to allow for ice-crystal nucleation and growth. The temperature was then increased to $-10{ }^{\circ} \mathrm{C}\left(1{ }^{\circ} \mathrm{C} / \mathrm{min}\right)$, followed by a hold of $24 \mathrm{~h}$ to allow for sublimation of the liquid phase, and then finally increased to room temperature $\left(0.5^{\circ} \mathrm{C} / \mathrm{min}\right)$. Scaffolds then underwent dehydrothermal crosslinking (DHT) as previously described in the literature (Haugh et al., 2009). The DHT process was performed in a vacuum oven (VD23, Binder, Germany), at $105{ }^{\circ} \mathrm{C}$, at $0.5 \mathrm{mbar}$ for $24 \mathrm{~h}$. This was then followed by a chemical cross-linking treatment using 1-Ethyl-3-(3dimethylaminopropyl) carbodiimide (EDAC; $6 \mathrm{mM}$ for $2 \mathrm{~h}$ with two washes in sterile phosphate buffered saline $2 \times 1 \mathrm{~h}$ ). Scaffolds were either seeded with cells for the in vitro analysis, or implanted cell-free for the in vivo study.

\section{Scanning Electron Microscopy (SEM)}

Scaffolds were imaged using SEM to visualise the internal porous structure of the freeze-dried constructs. Imaging was carried out following DHT treatment by fixing constructs to an adhesive carbon stub, sputter coating with gold, and imaging using a lens detector with a $5 \mathrm{kV}$ acceleration voltage at calibrated magnifications (Tescan Mira XMU, Tescan USA Inc.).

\section{Biochemical analysis of DNA, sGAG and calcium}

Scaffolds formed from native GP, and decellularised GP matrix were evaluated $(n=3)$ for their residual DNA, sulphated glycosaminoglycan (sGAG) and calcium content post fabrication. Scaffolds were digested with papain $\left(125 \mu \mathrm{g} \mathrm{mL}^{-1}\right)$ in $0.1 \mathrm{M}$ sodium acetate, $5 \mathrm{mM}$ L-cysteine$\mathrm{HCl}, 0.05 \mathrm{M}$ EDTA, pH 6.0 (all from Sigma-Aldrich) at $60{ }^{\circ} \mathrm{C}$ and $10 \mathrm{rpm}$ for $18 \mathrm{~h}$. DNA content was quantified using the Hoechst Bisbenzimide 33258 dye assay, with a calf thymus DNA standard (Sigma-Aldrich). The amount of sGAG was quantified using the dimethyl methylene blue (DMMB) dye-binding assay (Blyscan, Biocolor Ltd., Northern Ireland), with a chondroitin sulphate standard and both were normalised by scaffold weight. To quantify calcium deposition, scaffolds were chemically digested in $1 \mathrm{M} \mathrm{HCL}$ at $60{ }^{\circ} \mathrm{C}$ under rotation for $18 \mathrm{~h}$, and an O-cresolphthalein complexone (oCPC; Sentinel Diagnostics, Italy) assay was performed. Cell-seeded 
constructs were also analysed $(n=3)$ for their sGAG and calcium content following $28 \mathrm{~d}$ in culture using the same protocols.

\section{Innate immune response analysis}

Cytokine production measured by ELISA

In order to characterise the immune cell response to the native and decellularised GP scaffolds, primary human macrophages were seeded onto the scaffolds and analysed. Peripheral blood mononuclear cells (PBMC) were isolated by means of density gradient centrifugation from leukocyte-enriched buffy coats from anonymous healthy donors, obtained with permission from the Irish Blood Transfusion Board, St. James's Hospital, Dublin. CD14+ myeloid cells were purified from PBMC by means of positive selection using anti-CD14 magnetic beads according to the manufacturer's protocol (Miltenyi Biotech, Germany) (Corr et al., 2016; Safi et al., 2016). Cells were shown to be $>90 \%$ pure as determined by flow cytometry. $\mathrm{CD} 14^{+}$monocytes were differentiated into macrophages for $6 \mathrm{~d}$ in the presence and absence growth plate scaffolds using M-CSF (50 ng/mL). As a positive control, macrophages were also stimulated with $100 \mathrm{ng} / \mathrm{mL}$ LPS for $24 \mathrm{~h}$. Cytokine production was quantified in cell supernatants by ELISA (IL- $1 \beta$ and TNF, R\&D Systems; IL-12 and IL-8, eBiosciences).

\section{Real-time PCR}

Primary human macrophages $\left(7.5 \times 10^{\wedge}\right.$ cells $\left./ \mathrm{mL}\right)$ were polarised to an M1 phenotype with IFN $\gamma(10 \mathrm{ng} / \mathrm{mL})$ for $24 \mathrm{~h}$ in the presence and absence of native and decellularised GP scaffolds. RNA was extracted from cells using the High Pure RNA Isolation Kit (Roche, Basel, Switzerland) and assessed for concentration and purity using the NanoDrop 2000c UV-Vis spectrophotometer. RNA was equalised and reverse transcribed using the Applied Biosystems High-Capacity cDNA reverse transcription kit. Real-time quantitative PCR was carried out on triplicate cDNA samples with the use of the CFX96 Touch Real-Time PCR Detection System (Bio-Rad Laboratories, Hercules, California). Real-time PCR for the detection of CCL19 and CXCL11 mRNA was performed using the TaqMan fast universal PCR Master Mix (Applied Biosystems) and predesigned TaqMan gene expression primers. Amounts of mRNA were normalised relative to the housekeeping gene Ribosomal Protein 18S.

In vitro analysis with bone marrow derived MSCs Bone marrow derived mesenchymal stem cells (BMSCs) were harvested from the femora of porcine hind legs, and expanded using standard culture conditions. BMSCs were expanded to passage 2 and seeded onto the GP scaffold at a density of $0.5 \times 10^{\wedge} 6$ cells per scaffold. Cells were allowed to attach to the scaffolds for $1 \mathrm{~h}$ in the incubator at $37{ }^{\circ} \mathrm{C}$ before culturing in either chondrogenic or osteogenic medium for $28 \mathrm{~d}$ in normoxic conditions $\left(20 \% \mathrm{O}_{2}\right.$ and $5 \% \mathrm{CO}_{2}$ ). The constructs were cultured in $5 \mathrm{~mL}$ of either (i) chondrogenic media: Dulbecco's modified Eagle's medium (DMEM) + GlutaMAX ${ }^{\mathrm{TM}}$ (Gibco), 1 mM sodium pyruvate, $350 \mu \mathrm{M}$ L-proline, $1.5 \mathrm{mg} / \mathrm{mL}$ bovine serum albumin (BSA), $1 \mathrm{nM}$ dexamethasone, $300 \mu \mathrm{M}$ ascorbic acid, $17 \mu \mathrm{M}$ linolenic acid, $10 \mathrm{ng} / \mathrm{mL}$ transforming growth factor $\beta 3$ (TGF- $\beta 3$, ProSpec-Tany, Israel), $1 \mathrm{X}$ insulintransferrin-selenium; or (ii) osteogenic media: DMEM + GlutaMAX ${ }^{\mathrm{TM}}, 10 \%$ foetal bovine serum (Gibco), $10 \mathrm{mM}$ $\beta$-glycerophosphate, $1 \mathrm{nM}$ dexamethasone, $0.09 \mathrm{mM}$ ascorbic acid. Both media were supplemented with 100 units $/ \mathrm{mL}$ penicillin, 100 units $/ \mathrm{mL}$ streptomycin and $0.25 \mu \mathrm{g} / \mathrm{mL}$ amphotericin B.

\section{Histology and immunohistochemistry}

Samples were fixed in $4 \%$ paraformaldehyde (PFA) overnight, dehydrated in a graded series of ethanol and xylenes, and embedded in paraffin wax. In vivo samples were decalcified following fixation using an EDTA treatment (15\% EDTA at $\mathrm{pH} 7.4)$ to remove the mineral component prior to embedding. Sections of $8 \mu \mathrm{m}$ were obtained with a microtome (Leica RM2125RT) and affixed to microscope slides. Prior to staining, sections were dewaxed and rehydrated in 100-70 \% ethanol followed by distilled water. The deposition of sGAG, collagen and calcium over $28 \mathrm{~d}$ in vitro was evaluated using $1 \%$ alcian blue in $0.1 \mathrm{M} \mathrm{HCl}$, picrosirius red, and $1 \%$ alizarin red solutions respectively. Post-implantation samples were evaluated for cellular infiltration and bone matrix deposition with haematoxylin and eosin (H\&E) and deposition of sGAG with safranin-O (all Sigma-Aldrich). Evaluation of vessel number and bone area quantification were performed on histological samples stained for H\&E, by counting vessels visible across an entire section, under a microscope at $20 \times$, and using Adobe Photoshop and Image $\mathrm{J}$ to determine bone area.

Collagen type II and type X deposition was evaluated using a standard immunohistochemical technique (Sheehy et al., 2015). Briefly, sections ( $n=4$ sections per group) were treated with hydrogen peroxidase (Sigma-Aldrich), followed by enzymatic treatment with pronase $(0.5 \mathrm{mg} / \mathrm{mL}$, Merck Millipore) in a humidified environment for $5 \mathrm{~min}$ at $37^{\circ} \mathrm{C}$ to enhance the permeability of the ECM. Sections were incubated with goat serum to block non-specific sites and mouse monoclonal IgG anti-collagen type II (ab3092, 1:100) and mouse monoclonal IgM anti-collagen type X (ab49945, 1:200) primary antibodies (Abcam) were applied overnight at $4{ }^{\circ} \mathrm{C}$. Next, the secondary antibody (Collagen type II; goat anti-mouse IgG, 1:200, B7151 Sigma-Aldrich and Collagen type $\mathrm{X}$; goat anti-mouse IgM, 1:200, ab49760 Abcam, UK) was added for $1 \mathrm{~h}$, followed by incubation with $\mathrm{ABC}$ reagent (Vectastain PK-400, Vector Labs) for 45 min. Finally, sections were developed with DAB peroxidase (Vector Labs) for $5 \mathrm{~min}$. Positive and negative controls were included in the immunohistochemistry staining protocol for each batch.

\section{Cranial defect implantation}

A cranial defect was created in adult male Fischer rats following an established procedure (Lyons et al., 2010), with $n=4$ animals per group at two time points of 4 and 8 weeks. Anaesthesia was induced with an intraperitoneal injection of xylazine hydrochloride $(10 \mathrm{mg} / \mathrm{kg})$ and ketamine hydrochloride $(75 \mathrm{mg} / \mathrm{kg})$, and maintained with inhalational isoflurane and oxygen (0.5-2\% isoflurane). A $7 \mathrm{~mm}$ circular transosseous defect was created on the 
left side of the rat parietal calvarium using a grinding burr and the GP scaffold (decellularised but not EDTAtreated) was immediately implanted into the defect or left untreated for the empty defect (ED) groups before closing of the wound with sutures. Atipamezole hydrochloride was given to reverse sedation. Pain relief was administered via carprofen and buprenorphine subcutaneous injections over the following $2 \mathrm{~d}$. On dates of scheduled explant retrieval, rats were sacrificed by $\mathrm{CO}_{2}$ asphyxiation and cervical dislocation, and calvaria were harvested for evaluation. Ethical approval was given by the Research Ethics Committee of the Royal College of Surgeons in Ireland and an animal licence was granted by the Department of Health and Children (Ref. B100/4490) prior to initiation of study.

\section{Micro-computed tomography}

Micro-computed tomography $(\mu \mathrm{CT})$ scans were carried out on the explants from the cranial study in order to visualise and quantify mineral content and distribution. A Scanco Medical $40 \mu \mathrm{CT}$ system (Scanco Medical, Bassersdorf,
Switzerland) was used for evaluation with a $70 \mathrm{kVp}$ X-ray source at $114 \mu \mathrm{A}$. Four constructs were analysed per experimental group and per time point. Reconstructed 3D images were generated from the scans and used to visualise mineral distribution throughout the implanted scaffold or control group. Quantification was performed by setting a threshold of 165 , corresponding to $339 \mathrm{mg} \mathrm{HA} / \mathrm{cm}^{\wedge}$, and recording the bone volume (BV) within the defect per total volume $(\mathrm{BV} / \mathrm{TV})$, using a consistent total volume $(5 \mathrm{~mm}$ diameter and 50 slices in the $\mathrm{Z}$ direction, voxel size $20 \mu \mathrm{m}$ ) from sample to sample which eliminated original bone from the calculations (Cunniffe et al., 2016).

\section{Statistical Analysis}

All statistical analyses were carried out using GraphPad. The results are reported as means \pm standard deviation. Groups were analysed by a general linear model for analysis of variance with groups of factors. Tukey's test or student $t$-tests were used to compare groups. Significance was accepted at a level of $p<0.05$. a)

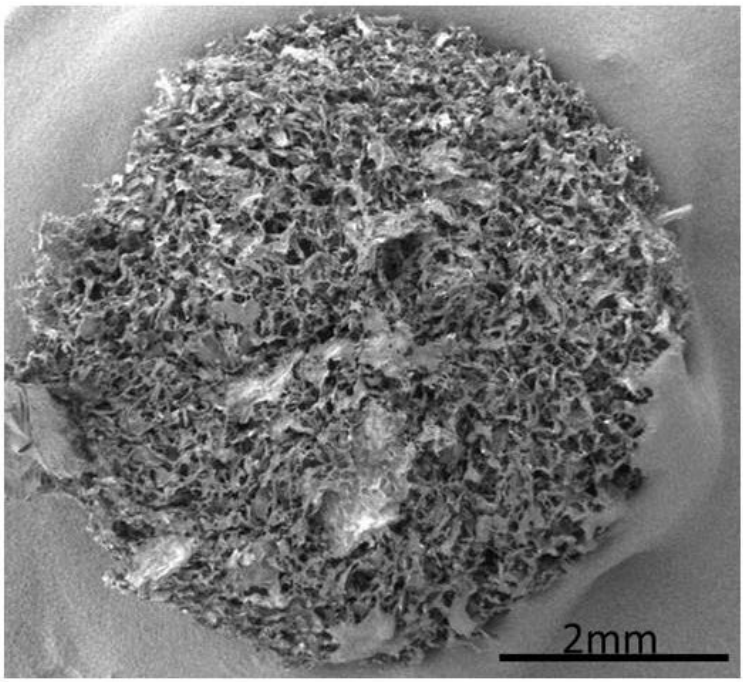

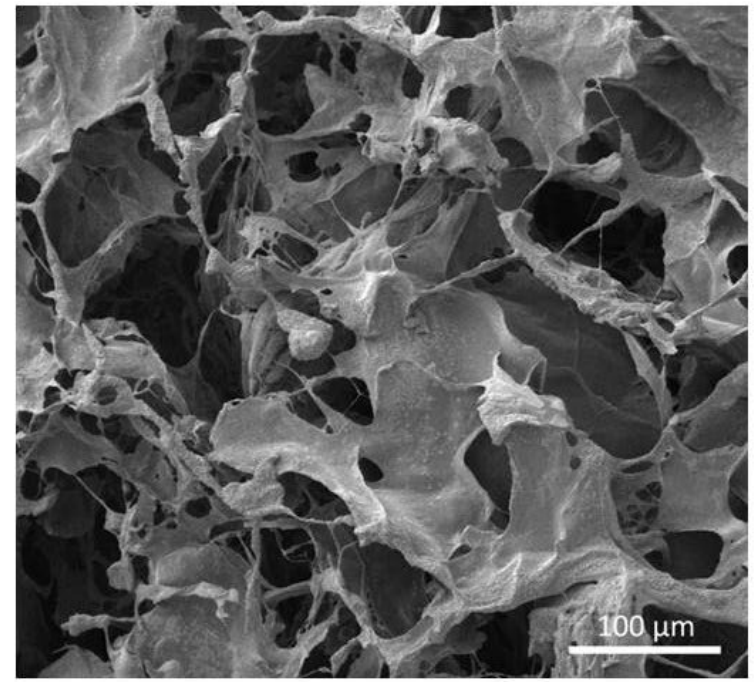

b)

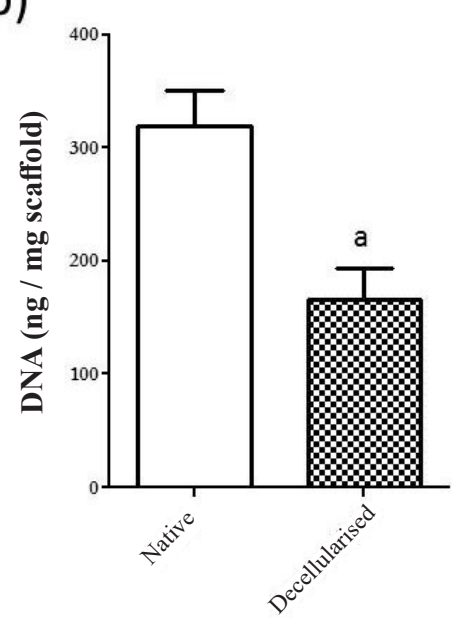

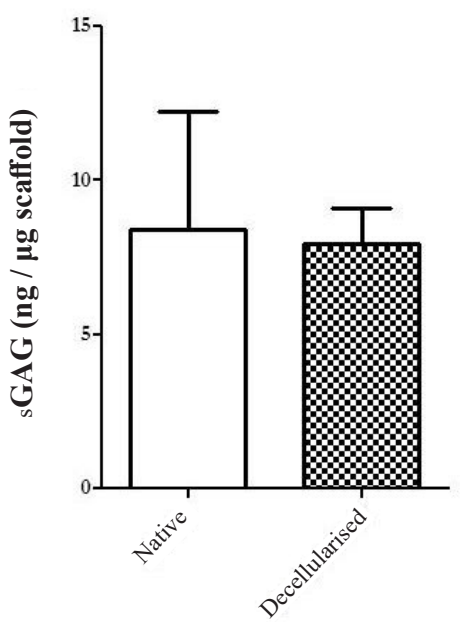

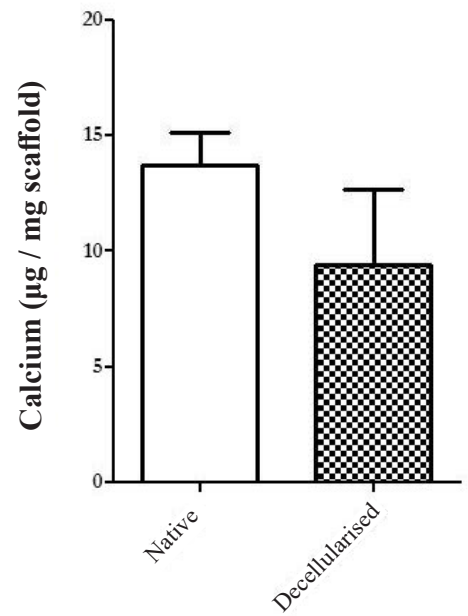

Fig. 1. a). Scanning electron microscopy (SEM) images of the GP scaffold indicating the open interconnected porosity achieved post-lyophilisation. b). Biochemical analysis of residual DNA, sGAG and calcium following the $0.1 \%$ SDS decellularisation treatment, compared to the native GP scaffold. (a) $\mathrm{p}<0.05$ (unpaired $t$-test). 
a)

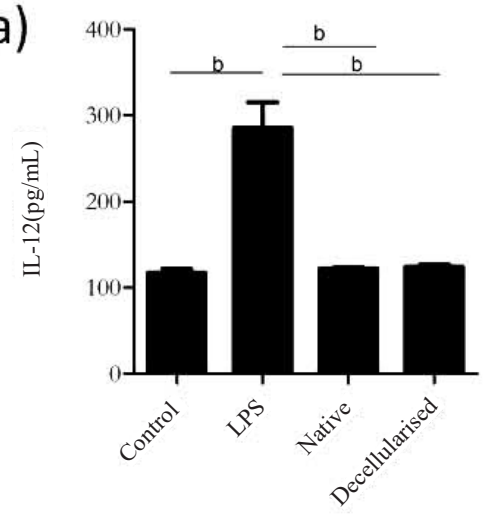

c)

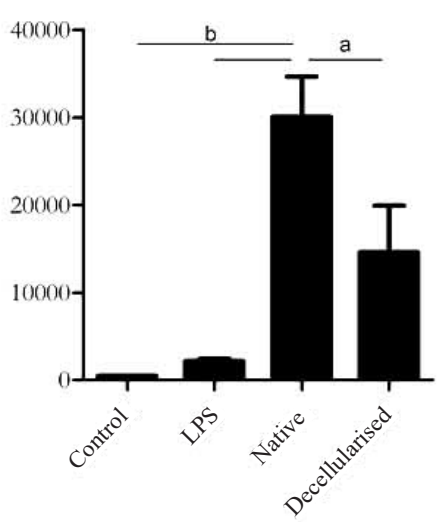

e)

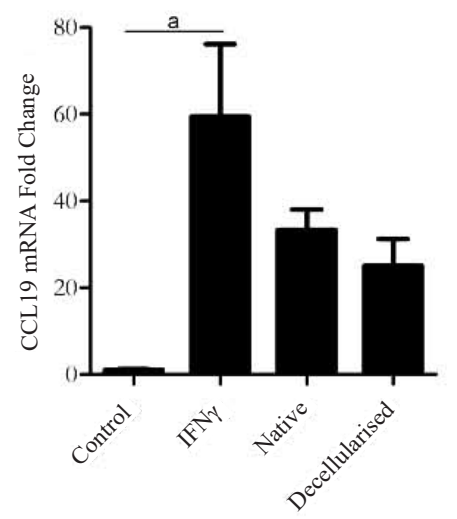

b)

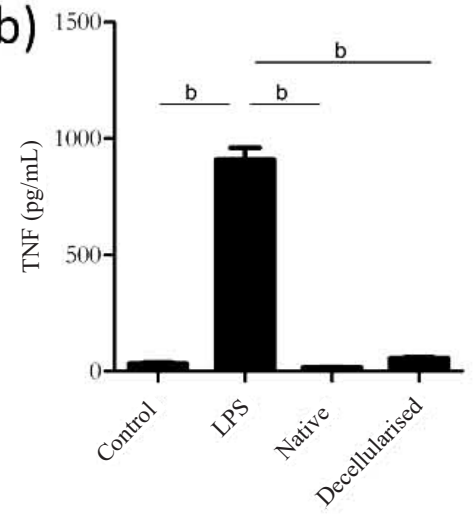

d)

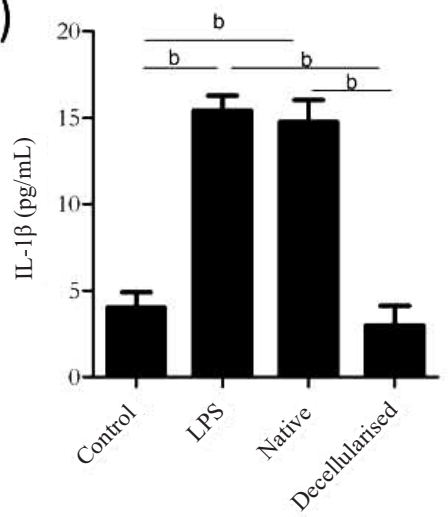

f)

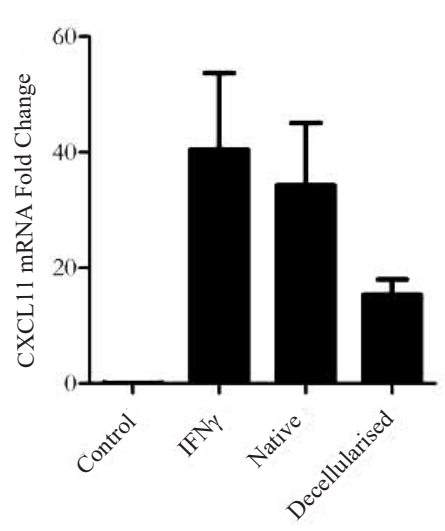

Fig. 2. a-d). The effect of growth plate scaffolds on cytokine production and macrophage phenotype. Human monocytes were differentiated into macrophages in the presence of native and $0.1 \%$ SDS treated growth plate for $6 \mathrm{~d}$. As a positive control, macrophages were treated with $100 \mathrm{ng} / \mathrm{mL}$ LPS for $24 \mathrm{~h}$. Cytokine production was quantified by ELISA. e,f). Macrophages were polarised to an M1 phenotype with IFN $\gamma(10 \mathrm{ng} /$ $\mathrm{mL}$ ) for $24 \mathrm{~h}$ in the presence and absence of scaffolds. The mRNA expression was quantified by realtime PCR. (b) $p<0.001$ and (a) $p<0.05$.

\section{Results}

\section{Porous scaffolds can be fabricated using porcine} Growth Plate (GP) ECM

Scaffolds were generated by lyophilisation of slurries of GP matrix, resulting in constructs with an open, interconnected porosity, with a mean pore size of $126 \pm 52 \mu \mathrm{m}$, suitable for cellular infiltration and migration (Fig. 1a). Biochemical analysis of decellularised GP ( $0.1 \%$ SDS treatment $)$ indicated that $\mathrm{SGAG}$ and calcium could be retained within the matrix, with no significant reduction in the levels of these ECM components compared to the untreated native GP control (Fig. 1b). A significant reduction in DNA content was observed following decellularisation.

The scaffolds were next assessed by culturing primary human macrophages in the presence of native and decellularised $(0.1 \%$ SDS) GP. LPS, a potent driver of pro-inflammatory cytokine production, was included as a positive control. No increase in IL-12 or TNF production was detected with either material (Fig. 2a,b). Robust
IL-8 production was observed in the supernatants of macrophages cultured with native GP; however this was significantly lower with decellularised GP(Fig. 2c). Native GP produced comparable levels of IL- $1 \beta$ to LPS and again this was reduced in the presence of the decellularised material (Fig. 2d).

The effect of the scaffolds on M1-associated macrophage polarisation was next assessed. In this case, macrophages were cultured in the presence of native and decellularised GP prior to treatment with the M1 polarising cytokine, IFN $\gamma$. As expected, IFN $\gamma$ increased the expression of the M1 associated genes, CCL19 and CXCL11, and this was not altered by the presence of the scaffolds (Fig. 2e,f).

MSC seeded GP ECM scaffolds mineralise in either chondrogenic or osteogenic culture conditions

Independent of the culture conditions, bone marrow derived MSCs cultured on GP scaffolds were observed to deposit a densely calcified matrix over $28 \mathrm{~d}$ in vitro (Fig. 3a,b). The constructs cultured in chondrogenic conditions stained 


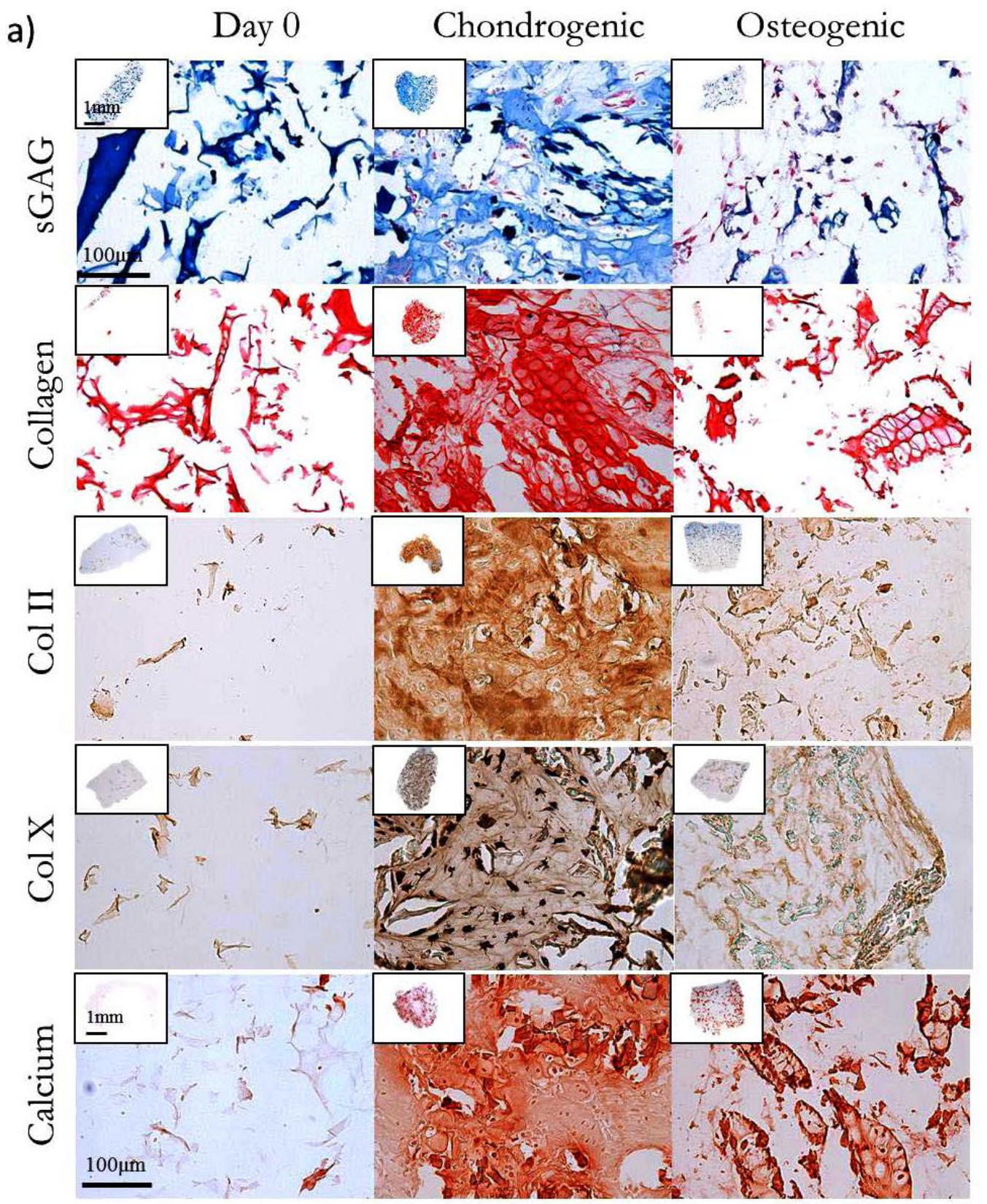

b)

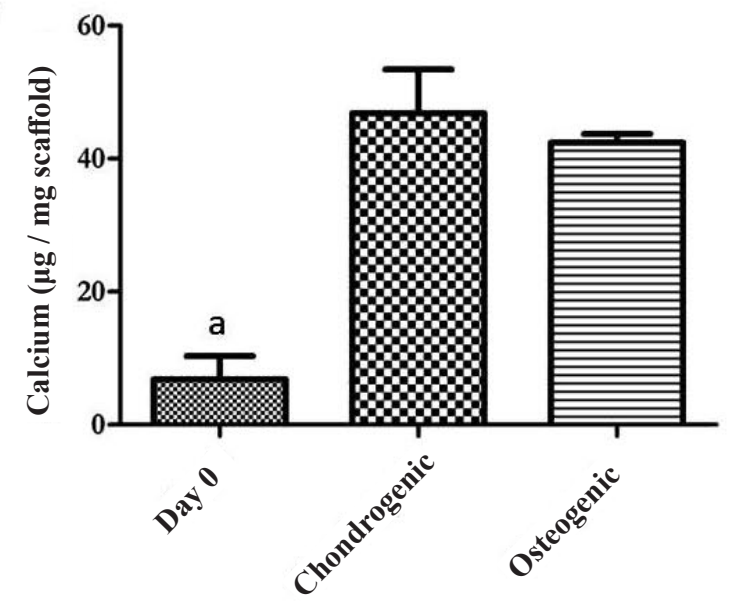

Fig. 3. a). Histological analysis of scaffolds at day 0 , and MSC-seeded constructs after $28 \mathrm{~d}$ in either chondrogenic or osteogenic conditions. Deposition of sGAG, collagen, collagen type II and X and calcium is observed, particularly in the construct cultured in chondrogenic medium. b). Biochemical analysis of the calcium deposited by MSCs over the culture period (a) $p<0.05$. 


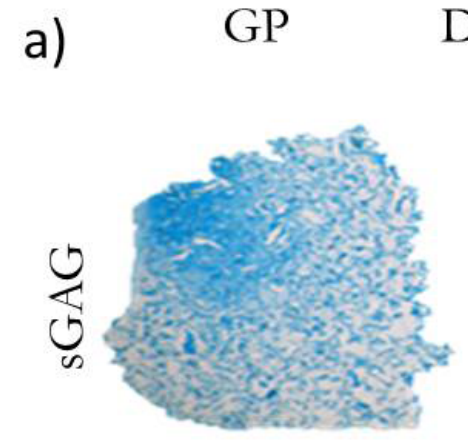

c)

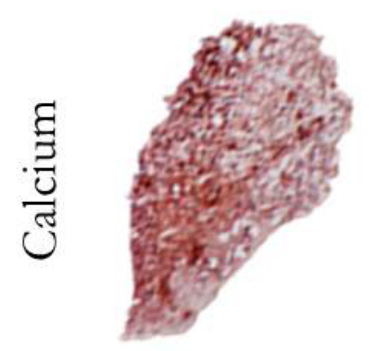

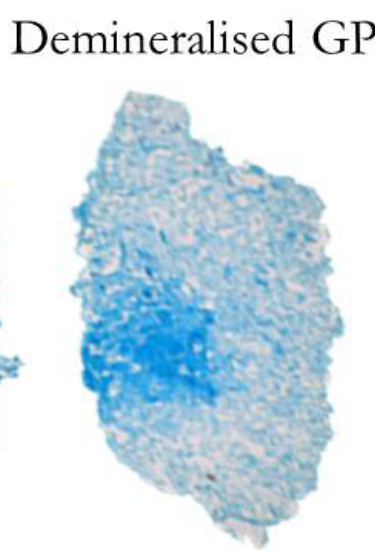

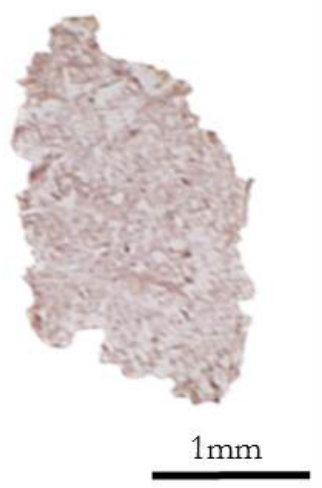

b)
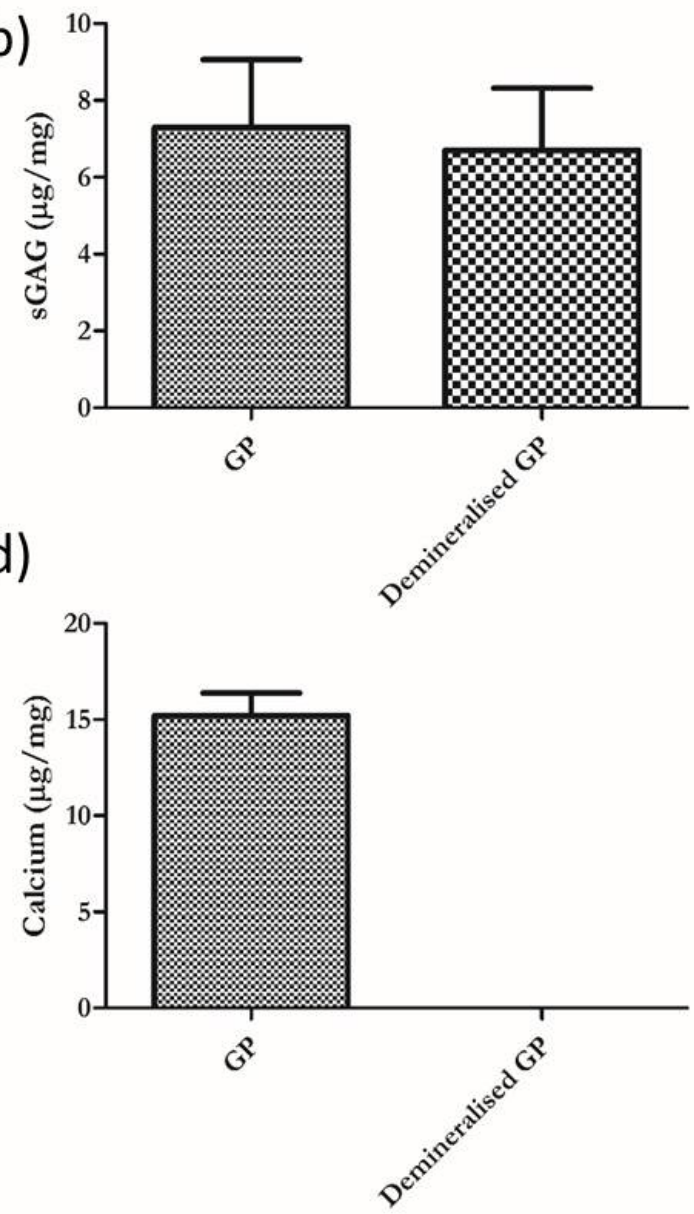

Fig. 4. a,b). Histological and biochemical analysis of sGAG deposition by MSCs at day 28 in chondrogenic culture conditions, seeded on a GP scaffold and a demineralised GP scaffold. c,d). Histological and biochemical analysis of calcium deposition occurring over the culture period on the GP and demineralised GP scaffolds.

more intensely for sGAG, collagen type II and type X after $28 \mathrm{~d}$ in culture compared to MSC-laden scaffolds cultured in osteogenic conditions, suggesting the development of a hypertrophic cartilage matrix that was calcifying in vitro. Quantification of the mineral deposition demonstrated that similar levels of calcium had accumulated within the scaffolds maintained in chondrogenic and osteogenic culture conditions (Fig. 3b).

In an attempt to elucidate the relative role of the unique collagenous matrix of the GP over other non-collagenous components in driving this cell-mediated mineral deposition, day 0 GP scaffolds were treated with EDTA in order to completely remove the mineral content prior to cell-seeding, leaving behind only a collagenous matrix (Day 0 calcium levels pre-decalcifying were $7.8 \pm 0.3 \mu \mathrm{g} /$ $\mathrm{mg}$ scaffold, and these values were subtracted from the day 28 results). Demineralised GP scaffolds were capable of supporting similar levels of sGAG accumulation over the $28 \mathrm{~d}$ in chondrogenic culture conditions; however, the ability of these scaffolds to induce mineralisation was significantly hampered (Fig. 4a-d), with no evidence of cell-mediated mineralisation detected in these constructs.
GP ECM derived scaffolds can accelerate endogenous bone regeneration in a critically-sized cranial defect Having demonstrated the osteogenicity of GP ECM scaffolds in vitro, we next implanted them cell-free into $7 \mathrm{~mm}$ cranial defects, with healing analysed 4 and 8 weeks after implantation and compared to untreated controls. Reconstructed 3D $\mu \mathrm{CT}$ images demonstrated the widespread deposition of bone at both time points post-implant (Fig. 5a,b). Upon closer inspection, small nodules of mineral were found homogeneously distributed throughout the defect. Quantification of the bone volume per total defect volume (BV/TV) demonstrated significantly greater levels of mineralised tissue at both 4 and 8 weeks vs. empty groups (Fig. 5c).

Histological analysis (H\&E) of the harvested samples demonstrated bone formation within the GP scaffold treated groups at 4 and 8 weeks, compared to predominantly fibrous tissue bridging the defect in the untreated group (Fig. 6a). Positive safranin-O staining for sGAG deposition was observed within the scaffold treated groups at 4 weeks, and to a lesser degree at 8 weeks (Fig. 6b). This appeared to be staining of the residual GP cartilage within the scaffold, 
a)
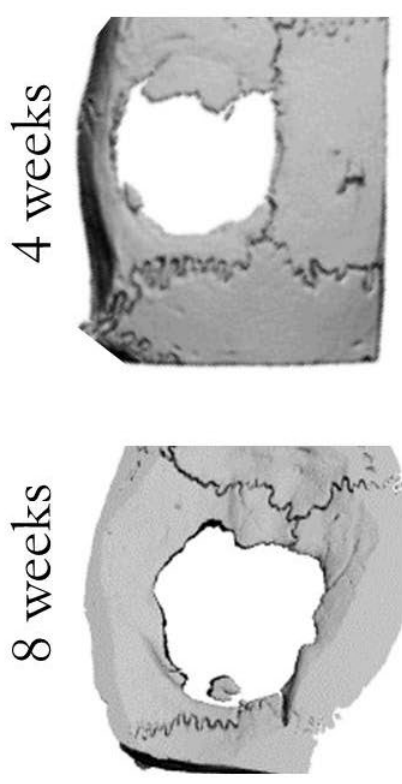

worst
Empty
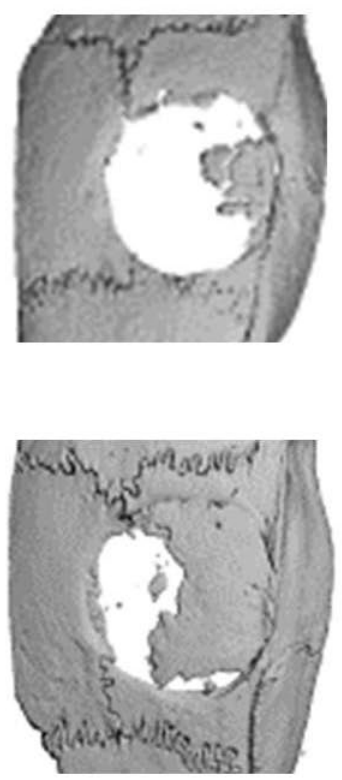

best

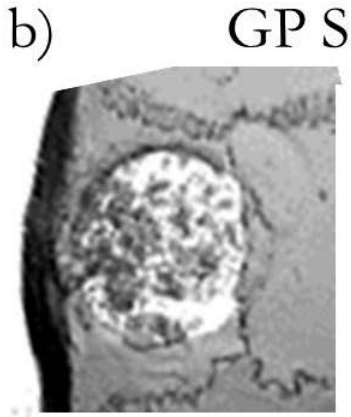

GP Scaffold

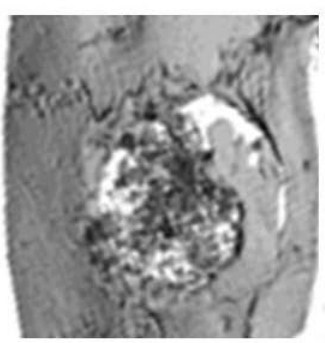

worst
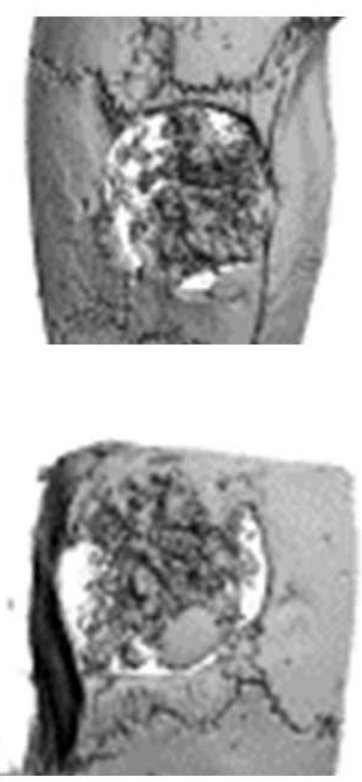

best

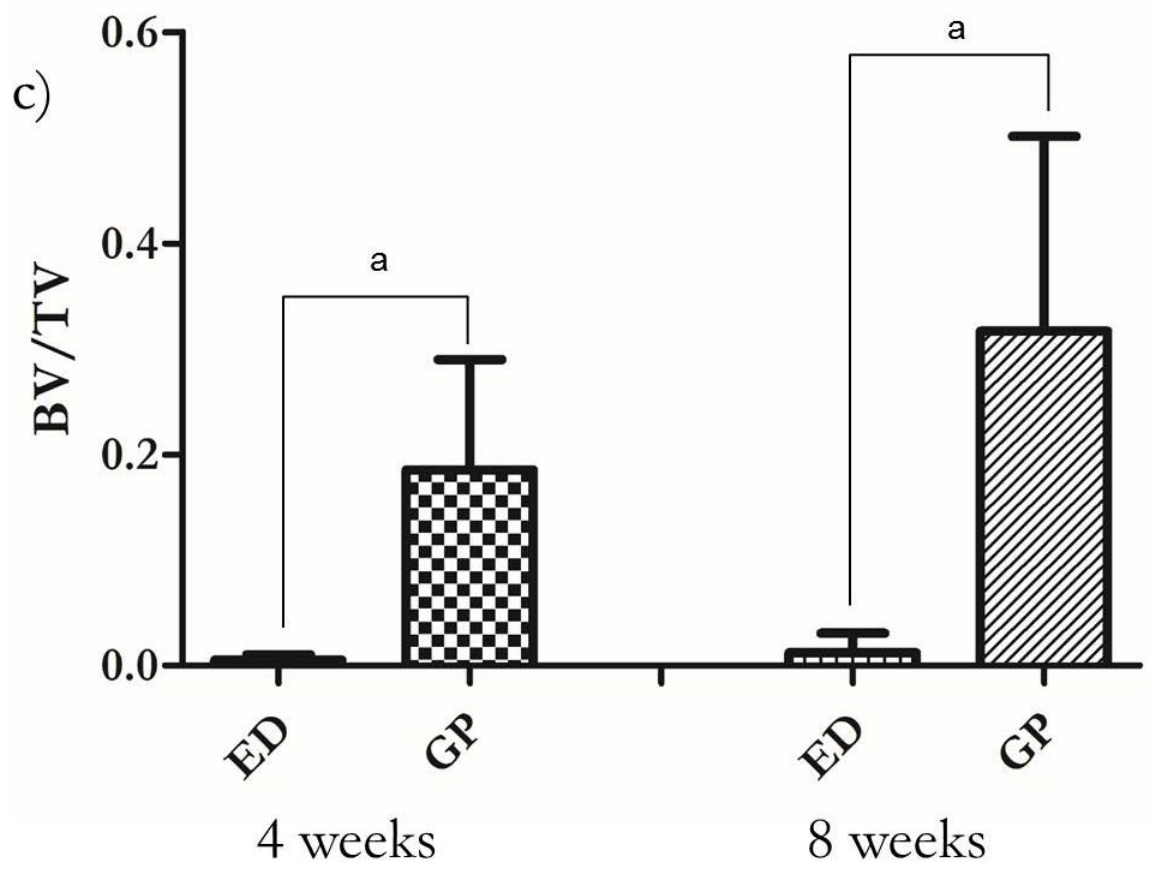

Fig. 5. a,b). Reconstructed $\mu \mathrm{CT}$ images indicate a distribution of mineral throughout GP scaffold treated defects, in comparison to the empty controls. c). A graph of the bone volume to total volume at both 4 and 8 weeks for GP treated and untreated (ED) groups. (a) $p<0.05$.

and not evidence of bone forming via endochondral ossification. In addition, histomorphometric analysis of H\&E stained slices allowed for determination of bone area within the defect, revealing a significant difference between the GP scaffold group and the empty control (Fig. 6c). Quantification of vessel number also indicated a significantly higher number of vessels were observed within the GP treated groups at both 4 and 8 weeks (Fig. 6d).

\section{Discussion}

The overall goal of this study was to develop porous scaffolds from GP ECM and to evaluate its potential as a biomaterial for promoting bone regeneration. The innate immune response of the scaffolds was assessed by culturing with primary human macrophages, which demonstrated that decellularisation resulted in reduced IL- $1 \beta$ and IL-8 production. These decellularised scaffolds were able to support osteogenesis of MSCs in vitro in both osteogenic 

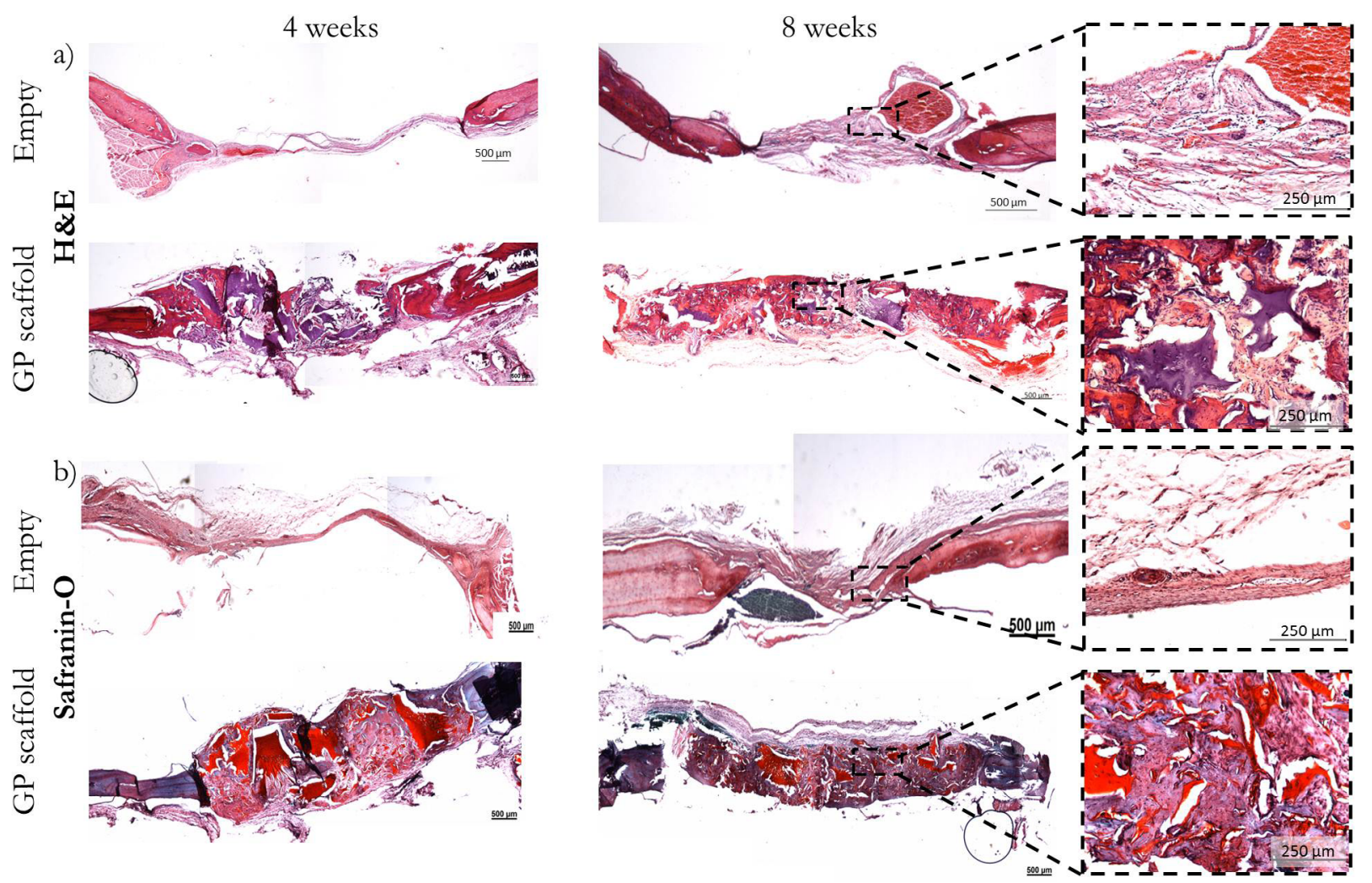

c)

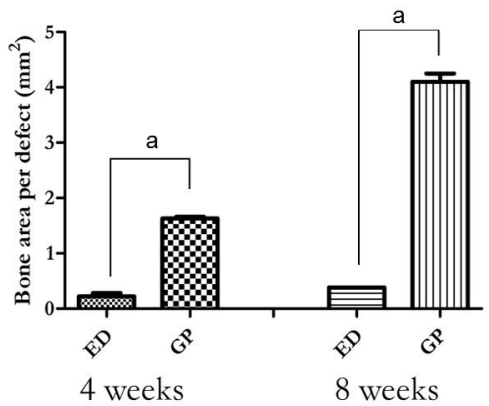

d)

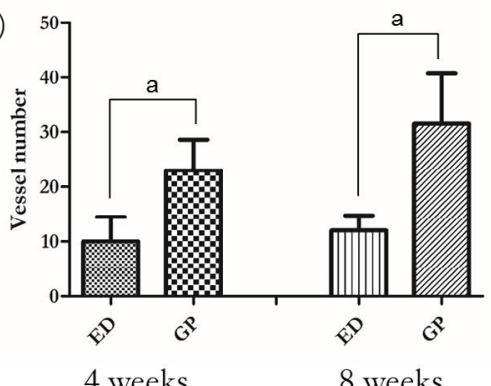

Fig. 6. a-b). Histological analysis of GP scaffold treated and empty cranial defects at 4 and 8 weeks post implantation, indicating de novo bone formation, sGAG, and collagen/connective tissue deposition. Higher magnification images are presented for the 8 week images. $\mathbf{c}, \mathbf{d})$. Quantification of the bone area per defect and vessel number within the defect at both time points (ED; empty defect, GP; growth plate). (a) $p<0.05$.

and chondrogenic culture conditions, and their acellular implantation into a critically-sized defect accelerated vascularisation and endogenous bone formation and repair. Taken together, these findings indicate the potential of this novel ECM derived biomaterial for large bone defect healing.

Calcified tissue was observed in MSC-seeded GP scaffolds cultured in both chondrogenic and osteogenic conditions after $28 \mathrm{~d}$ in vitro. The presence of collagen type II, type $\mathrm{X}$ and sGAG indicate that the mineralisation achieved in chondrogenic media was occurring via an endochondral route compared to that arising in the constructs cultured in osteogenic media. GP scaffolds seeded with MSCs and cultured in standard expansion medium (containing serum) also extensively mineralised (data not shown). Interestingly, however, when the GP scaffold was further treated with a decalcifying agent prior to cell seeding, the matrix failed to induce any cell-mediated mineral deposition when maintained in chondrogenic culture conditions. This would suggest that the relatively low mineral component within the GP is a dominant osteoinductive component rather than the collagenous matrix itself, although at this stage we cannot rule out a potential role for other non-collagenous proteins and growth factors that may be removed by EDTA treatment. Further proteomic analysis of the GP post scaffold fabrication is required to fully identify the key matrix components influencing cell differentiation and bone formation.

Successful integration of ECM scaffolds is dependent on appropriate host immune responses; therefore, preliminary assays were carried out to examine their effect on primary human macrophages. The production of key pro-inflammatory cytokines and chemokines was assessed and, as demonstrated, the production of IL-12, which links innate and adaptive immune responses was minimal. This was also the case for the highly inflammatory cytokine, TNF $\alpha$. Interestingly, native GP induced high 
levels of the chemokine, IL- 8 , which is a key driver of neutrophil chemotaxis and has the potential to exacerbate inflammatory responses. Importantly, decellularisation of GP with $0.1 \%$ SDS reduced IL- 8 production by approximately $50 \%$. It will be interesting to determine the precise role played by this chemokine in host interactions with ECM scaffolds. Of note, it has been shown that IL-8 can promote osteoclastogenesis (Kopesky et al., 2014); therefore, a certain level of this protein may actually be beneficial for optimal remodelling. We also assessed the effect of the scaffolds on macrophage phenotype given that they are likely to be implanted into an inflammatory micro-environment. Encouragingly, the scaffolds did not enhance the expression of genes that are associated with an inflammatory M1 macrophage phenotype. Furthermore, treatment with SDS appeared to reduce the expression of some M1 associated markers.

The only evidence of native GP material being used to treat bone defects, to the best of our knowledge, was in a series of recent studies where GP tissue was demineralised in a manner similar to bone matrix (DBM), and the resultant powder used to fill bone defects. This demineralised GP powder demonstrated an ability to achieve mineralisation in vivo, both ectopically in rat muscle, and orthopically in a rat spine defect and a rabbit radial defect study (BighamSadegh et al., 2014; Bigham et al., 2011; Shadkhast and Bighamsadegh, 2011). These studies pointed to the presence of potent growth factors from the TGF- $\beta$ super-family within the GP matrix as potentially leading to the observed bone deposition. In a similar study, the authors reported enhanced bone formation when the demineralised GP powder was supplemented with synthetic hydroxyapatite (Bigham-Sadegh et al., 2015). This may be related to the in vitro results observed in this study, where EDTA treatment to remove the calcium within the GP scaffolds was found to dramatically reduce their capacity to support an endochondral phenotype.

Analysis of defects treated with an acellular GP scaffold illustrated that endogenous cells were capable of infiltrating throughout the porous scaffold, facilitating mineralisation and de novo bone formation by 4 weeks. Quantification of the bone volume also indicates the beneficial effect of implanting the GP scaffold, with enhanced levels observed by 4 weeks. This distribution throughout the implanted material is highly favourable, as constructs can often become surrounded by new tissue, with mineralisation observed predominantly on the periphery of the implanted material, leading to core necrosis and implant failure (Lyons et al., 2010). The high porosity of the scaffold clearly facilitated excellent cell infiltration and vessel ingrowth, which ultimately contributed to the enhanced bone formation observed throughout the defect. The GP matrix is known to contain potent angiogenic growth factors which may have played a role in enhancing angiogenesis within the scaffold treated defects (Qiu et al., 2015). Comparable studies in the literature, using collagen based scaffolds to treat rat cranial defects, have demonstrated the need to incorporate exogenous factors such as BMP-2 (Quinlan et al., 2015b) and/or VEGF (Curtin et al., 2014) to induce robust bone healing. The fact that GP derived scaffolds can promote healing without the need for the additional delivery of exogenous factors such as BMP-2, which can have potent off-target effects (Benglis et al., 2008; Cahill et al., 2009), points to their potential use as a safe, lowcost and effective biomaterial for the repair or large bone defects. It should be noted, however, that our studies have been performed in relatively low-load bearing defects, and follow-up studies are required to assess their efficacy in more mechanically challenging locations.

While positive staining for cartilage specific matrix components was observed in scaffold treated defects, this was predominately staining of residual scaffold material and not necessarily evidence of endochondral bone healing, although we cannot completely rule out the possibility of this occurring. Cranial bones form via intramembranous ossification during embryonic development, although previous studies have also shown that healing in this region can occur along the endochondral route (Jukes et al., 2008; Lin et al., 2013). Future studies are required to further quantify the exact temporal patterns of repair within defects treated with GP ECM derived scaffolds.

Analysing the quality of the de novo tissue forming in more detail showed that newly deposited bone was replacing the GP ECM scaffold, with remodelling of the scaffold evident between week 4 and 8 , as demonstrated by a reduction in residual scaffold material within the defect over time. However, it should be noted that there was some variability observed within scaffolds, due to the different sizes of GP particles used to form the 3D scaffolds. This limitation can be avoided in future studies through the use of a cryo-mill which can generate a more homogeneous GP particle size range, which would lead to less variation from batch to batch (Almeida et al., 2015). In addition, more stringent decellularisation protocols will be developed, which will be particularly important when translating this scaffold material towards clinical applications (Badylak, 2004); however, no evidence of a chronic immune response was detected at either time point in the scaffold treated groups.

\section{Conclusions}

This study provides data to support the use of scaffolds derived from decellularised growth plate ECM for the repair of critically-sized bone defects. MSCs seeded on the GP scaffold in vitro underwent robust osteogenesis in both chondrogenic and osteogenic culture conditions. Upon implantation within a critically-sized cranial defect, the acellular GP scaffold facilitated endogenous cell infiltration and the deposition of a mineralised de novo bone matrix, with significantly more blood vessels and higher levels of bone formation compared to the empty controls, illustrating the potential of GP ECM as a biomaterial for bone regeneration. These scaffolds are relatively easy to produce in a process that could be readily scaled up. The fact that these scaffolds promote enhanced bone healing without the requirement for functionalisation with endogenous factors such as BMP-2 points to their potential as a safe and cost-effective biomaterial for treating large bone defects. 


\section{Acknowledgements}

Funding for this work was provided by AO under the large bone defect healing program, Science Foundation Ireland (12/IA/1554) in addition to the Health Research Board of Ireland (Grant No. HRA_POR/2011/27) and the European Research Council (ERC Grant Agreement No. 239685).

\section{References}

Aghdasi B, Montgomery SR, Daubs MD, Wang JC (2013) A review of demineralized bone matrices for spinal fusion: the evidence for efficacy. Surgeon 11: 39-48.

Alini M, Matsui Y, Dodge G, Poole AR (1992) The extracellular matrix of cartilage in the growth plate before and during calcification: Changes in composition and degradation of type II collagen. Calcif Tissue Int 50: 327 335 .

Almeida HV, Cunniffe GM, Vinardell T, Buckley CT, O'Brien FJ, Kelly DJ (2015) Coupling freshly isolated CD44(+) infrapatellar fat pad-derived stromal cells with a TGF-beta3 eluting cartilage ECM-derived scaffold as a single-stage strategy for promoting chondrogenesis. Adv Healthc Mater 4: 1043-1053.

Almeida HV, Liu Y, Cunniffe GM, Mulhall KJ, Matsiko A, Buckley CT, O’Brien FJ, Kelly DJ (2014) Controlled release of transforming growth factor- $\beta 3$ from cartilageextra-cellular-matrix-derived scaffolds to promote chondrogenesis of human-joint-tissue-derived stem cells. Acta Biomater 10: 4400-4409.

An HS, Simpson JM, Glover JM, Stephany J (1995) Comparison between allograft plus demineralized bone matrix versus autograft in anterior cervical fusion: a prospective multicenter study. Spine 20: 2211-2216.

Anderson HC, Hodges PT, Aguilera XM, Missana L, Moylan PE (2000) Bone morphogenetic protein (BMP) localization in developing human and rat growth plate, metaphysis, epiphysis, and articular cartilage. J Histochem Cytochem 48: 1493-1502.

Badylak SF (2004) Xenogeneic extracellular matrix as a scaffold for tissue reconstruction. Transpl Immunol 12: 367-377.

Benders KEM, Weeren PRv, Badylak SF, Saris DBF, Dhert WJA, Malda J (2013) Extracellular matrix scaffolds for cartilage and bone regeneration. Trends Biotechnol 31: 169-176.

Benglis D, Wang MY, Levi AD (2008) A comprehensive review of the safety profile of bone morphogenetic protein in spine surgery. Neurosurgery 62: 423-431.

Bigham-Sadegh A, Karimi I, Oryan A, Mahmoudi E, Shafiei-Sarvestani Z (2014) Spinal fusion with demineralized calf fetal growth plate as novel biomaterial in rat model: a preliminary study. Int J Spine Surg 8: doi: 10.14444/1005.

Bigham-Sadegh A, Karimi I, Shadkhast M, Mahdavi MH (2015) Hydroxyapatite and demineralized calf fetal growth plate effects on bone healing in rabbit model. $\mathrm{J}$ Orthop Traumatol 16: 141-149.

Bigham AS, Shadkhast M, Bigham Sadegh A, Shafiei Z, Lakzian A, Khalegi MR (2011) Evaluation of osteoinduction properties of the demineralized bovine foetal growth plate powder as a new xenogenic biomaterial in rat. Res Vet Sci 91: 306-310.

Cahill KS, Chi JH, Day A, Claus EB (2009) Prevalence, complications, and hospital charges associated with use of bone-morphogenetic proteins in spinal fusion procedures. JAMA 302: 58-66.

Calabrese G, Giuffrida R, Fabbi C, Figallo E, Lo Furno D, Gulino R, Colarossi C, Fullone F, Giuffrida R, Parenti R, Memeo L, Forte S (2016) Collagen-hydroxyapatite scaffolds induce human adipose derived stem cells osteogenic differentiation in vitro. PLoS one 11: e0151181. doi: 10.1371/journal.pone.0151181.

Carlevaro MF, Cermelli S, Cancedda R, Descalzi Cancedda F (2000) Vascular endothelial growth factor (VEGF) in cartilage neovascularization and chondrocyte differentiation: auto-paracrine role during endochondral bone formation. J Cell Sci 113: 59-69.

Chen G, Lv Y, Dong C, Yang L (2015) Effect of internal structure of collagen/hydroxyapatite scaffold on the osteogenic differentiation of mesenchymal stem cells. Curr Stem Cell Res Ther 10: 99-108.

Cheng CW, Solorio LD, Alsberg E (2014) Decellularized tissue and cell-derived extracellular matrices as scaffolds for orthopaedic tissue engineering. Biotechnol Adv 32: 462-484.

Corr EM, Cunningham CC, Dunne A (2016) Cholesterol crystals activate Syk and PI3 kinase in human macrophages and dendritic cells. Atherosclerosis 251: 197-205.

Cunniffe GM, Curtin CM, Thompson EM, Dickson GR, O'Brien FJ (2016) Content-dependent osteogenic response of nanohydroxyapatite: an in vitro and in vivo assessment within collagen-based scaffolds. ACS Appl Mater Interfaces 8: 23477-23488.

Cunniffe GM, Dickson GR, Partap S, Stanton KT, O'Brien FJ (2010) Development and characterisation of a collagen nano-hydroxyapatite composite scaffold for bone tissue engineering. J Mater Sci Mater Med 21: 2293-2298.

Cunniffe GM, O'Brien FJ (2011) Collagen scaffolds for orthopedic regenerative medicine. JOM 63: 66-73.

Cunniffe GM, Vinardell T, Murphy JM, Thompson EM, Matsiko A, O’Brien FJ, Kelly DJ (2015) Porous decellularized tissue engineered hypertrophic cartilage as a scaffold for large bone defect healing. Acta Biomater 23: 82-90.

Curtin CM, Tierney EG, McSorley K, Cryan SA, Duffy GP, O’Brien FJ (2014) Combinatorial gene therapy accelerates bone regeneration: non-viral dual delivery of VEGF and BMP2 in a collagen-nanohydroxyapatite scaffold. Adv Healthc Mater 4: 223-227.

David F, Levingstone TJ, Schneeweiss W, de Swarte M, Jahns H, Gleeson JP, O'Brien FJ (2015) Enhanced bone healing using collagen-hydroxyapatite scaffold implantation in the treatment of a large multiloculated mandibular aneurysmal bone cyst in a thoroughbred filly. J Tissue Eng Regen Med 9: 1193-1199.

Dimitriou R, Jones E, McGonagle D, Giannoudis PV (2011) Bone regeneration: current concepts and future directions. BMC Med 9: 66. doi: 10.1186/1741-7015-9-66.

Gerber HP, Vu TH, Ryan AM, Kowalski J, Werb Z, Ferrara N (1999) VEGF couples hypertrophic cartilage 
remodeling, ossification and angiogenesis during endochondral bone formation. Nat Med 5: 623-628.

Gilbert TW, Sellaro TL, Badylak SF (2006) Decellularization of tissues and organs. Biomaterials 27: 3675-3683.

Gleeson JP, Plunkett NA, O’Brien FJ (2010) Addition of hydroxyapatite improves stiffness, interconnectivity and osteogenic potential of a highly porous collagen-based scaffold for bone tissue regeneration. Eur Cell Mater 20: 218-230.

Gruskin E, Doll BA, Futrell FW, Schmitz JP, Hollinger JO (2012) Demineralized bone matrix in bone repair: History and use. Adv Drug Deliv Rev 64: 1063-1077.

Haugh MG, Jaasma MJ, O'Brien FJ (2009) The effect of dehydrothermal treatment on the mechanical and structural properties of collagen-GAG scaffolds. J Biomed Mater Res A 89: 363-369.

Jin CZ, Park SR, Choi BH, Park K, Min B-H (2007) In vivo cartilage tissue engineering using a cell-derived extracellular matrix scaffold. Artif Organs 31: 183-192.

Jukes JM, Both SK, Leusink A, Sterk LMT, Van Blitterswijk CA, De Boer J (2008) Endochondral bone tissue engineering using embryonic stem cells. Proc Natl Acad Sci U S A 105: 6840-6845.

Karageorgiou V, Kaplan D (2005) Porosity of 3D biomaterial scaffolds and osteogenesis. Biomaterials 26: 5474-5491.

Kheir E, Stapleton T, Shaw D, Jin Z, Fisher J, Ingham E (2011) Development and characterization of an acellular porcine cartilage bone matrix for use in tissue engineering. J Biomed Mater Res A 99: 283-294.

Kim IG, Hwang MP, Du P, Ko J, Ha C-w, Do SH, Park K (2015) Bioactive cell-derived matrices combined with polymer mesh scaffold for osteogenesis and bone healing. Biomaterials 50: 75-86.

Kopesky P, Tiedemann K, Alkekhia D, Zechner C, Millard B, Schoeberl B, Komarova SV (2014) Autocrine signaling is a key regulatory element during osteoclastogenesis. Biol Open 3: 767-776.

Kronenberg HM (2003) Developmental regulation of the growth plate. Nature 423: 332-336.

Lau TT, Lee LQP, Vo BN, Su K, Wang D-A (2012) Inducing ossification in an engineered 3D scaffold-free living cartilage template. Biomaterials 33: 8406-8417.

Lin C-Y, Chang Y-H, Li K-C, Lu C-H, Sung L-Y, Yeh C-L, Lin K-J, Huang S-F, Yen T-C, Hu Y-C (2013) The use of ASCs engineered to express BMP2 or TGF- $\beta 3$ within scaffold constructs to promote calvarial bone repair. Biomaterials 34: 9401-9412.

Lu H, Hoshiba T, Kawazoe N, Chen G (2011) Autologous extracellular matrix scaffolds for tissue engineering. Biomaterials 32: 2489-2499.

Luo L, Chu JYJ, Eswaramoorthy R, Mulhall KJ, Kelly DJ (2016) Engineering tissues that mimic the zonal nature of articular cartilage using decellularized cartilage explants seeded with adult stem cells. ACS Biomater. Sci. Eng. doi: 10.1021/acsbiomaterials.6b00020

Luo L, Eswaramoorthy R, Mulhall KJ, Kelly DJ (2015) Decellularization of porcine articular cartilage explants and their subsequent repopulation with human chondroprogenitor cells. J Mech Behav Biomed Mater 55: 21-31.

Lyons FG, Al-Munajjed AA, Kieran SM, Toner ME, Murphy CM, Duffy GP, O'Brien FJ (2010) The healing of bony defects by cell-free collagen-based scaffolds compared to stem cell-seeded tissue engineered constructs. Biomaterials 31: 9232-9243.

Murphy CM, Haugh MG, O’Brien FJ (2010) The effect of mean pore size on cell attachment, proliferation and migration in collagen-glycosaminoglycan scaffolds for bone tissue engineering. Biomaterials 31: 461-466.

Nilsson O, Parker EA, Hegde A, Chau M, Barnes KM, Baron J (2007) Gradients in bone morphogenetic protein-related gene expression across the growth plate. $\mathrm{J}$ Endocrinol 193: 75-84.

O’Brien FJ, Harley BA, Waller MA, Yannas IV, Gibson LJ, Prendergast PJ (2007) The effect of pore size on permeability and cell attachment in collagen scaffolds for tissue engineering. Technol Health Care 15: 3-17.

Pati F, Song TH, Rijal G, Jang J, Kim SW, Cho DW (2015) Ornamenting 3D printed scaffolds with celllaid extracellular matrix for bone tissue regeneration. Biomaterials 37: 230-241.

Pattabhi SR, Martinez JS, Keller Iii TCS (2014) Decellularized ECM effects on human mesenchymal stem cell stemness and differentiation. Differentiation 88: 131143.

Prosecka E, Rampichova M, Litvinec A, Tonar Z, Kralickova M, Vojtova L, Kochova P, Plencner M, Buzgo M, Mickova A, Jancar J, Amler E (2015) Collagen/ hydroxyapatite scaffold enriched with polycaprolactone nanofibers, thrombocyte-rich solution and mesenchymal stem cells promotes regeneration in large bone defect in vivo. J Biomed Mater Res A 103: 671-682.

Qiu T, Xian L, Crane J, Wen C, Hilton M, Lu W, Newman P, Cao X (2015) PTH receptor signaling in osteoblasts regulates endochondral vascularization in maintenance of postnatal growth plate. J Bone Miner Res 30: 309-317.

Quinlan E, Lopez-Noriega A, Thompson EM, Hibbitts A, Cryan SA, O’Brien FJ (2015a) Controlled release of vascular endothelial growth factor from spray-dried alginate microparticles in collagen-hydroxyapatite scaffolds for promoting vascularization and bone repair. J Tissue Eng Regen Med. doi: 10.1002/term.2013.

Quinlan E, Thompson EM, Matsiko A, O'Brien FJ, Lopez-Noriega A (2015b) Long-term controlled delivery of rhBMP-2 from collagen-hydroxyapatite scaffolds for superior bone tissue regeneration. J Control Release 207: 112-119.

Safi W, Kuehnl A, Nüssler A, Eckstein H-H, Pelisek J (2016) Differentiation of human CD14+ monocytes: an experimental investigation of the optimal culture medium and evidence of a lack of differentiation along the endothelial line. Exp Mol Med 48: e227. doi: 10.1038/ emm.2016.11.

Samorezov JE, Alsberg E (2015) Spatial regulation of controlled bioactive factor delivery for bone tissue engineering. Adv Drug Deliv Rev 84: 45-67. 
Shadkhast M, Bighamsadegh A (2011) Demineralized calf foetal growth plate effects on experimental bone healing. Bone 48: S168.

Sheehy EJ, Mesallati T, Kelly L, Vinardell T, Buckley CT, Kelly DJ (2015) Tissue engineering whole bones through endochondral ossification: regenerating the distal phalanx. Biores Open Access 4: 229-241.

Solheim E (1998) Growth factors in bone. Int Orthop 22: 410-416.

Sutherland AJ, Converse GL, Hopkins RA, Detamore MS (2015) The bioactivity of cartilage extracellular matrix in articular cartilage regeneration. Adv Healthc Mater 4: 29-39.

Tilkeridis K, Touzopoulos P, Ververidis A, Christodoulou S, Kazakos K, Drosos GI (2014) Use of demineralized bone matrix in spinal fusion. World J Orthop 5: 30-37.

Villa MM, Wang L, Huang J, Rowe DW, Wei M (2015) Bone tissue engineering with a collagen-hydroxyapatite scaffold and culture expanded bone marrow stromal cells. J Biomed Mater Res B Appl Biomater 103: 243-253.

Wang Y, Middleton F, Horton JA, Reichel L, Farnum CE, Damron TA (2004) Microarray analysis of proliferative and hypertrophic growth plate zones identifies differentiation markers and signal pathways. Bone 35: 1273-1293.

\section{Discussion with reviewers}

Reviewer 1: Do the authors have an idea which non collagneous ECM proteins would be removed by EDTA and which would be likely to remain in the demineralised scaffold?

Authors: EDTA treatment step is a commonly used decalcifying agent, although its complete effects are not easy to evaluate. It has been demonstrated that EDTA removes calcium phosphate, bone sialoprotein and decorin from bone tissue (Gerstenfeld et al., 1994), while others indicate that it removes phosphoproteins from teeth in addition to calcium and diffusible phosphate (Dimuzio and Veis, 1978). We have not studied the specific components that are being removed from the growth plate tissue, and hope to accomplish this in the future with in depth proteomic analysis. We believe that the major component removed is the mineral phase, but wanted to account for the fact that other non-collagenous proteins may also be removed during EDTA treatment.

In our osteogenic culture conditions, all scaffolds tend to support robust cell differentiation down an osteogenic pathway, with high levels of mineral deposition achieved by day 28 . Subtle differences are not easily observed using these potent osteogenic culture conditions, and as such, were not included within this section.

The EDTA treated scaffold "Demineralised GP" stained positively for collagen (Fig. 7); however, we did not do immunohistochemistry for specific Col X presence. We believe the collagens present to be similar to those observed in the non-EDTA treated GP scaffolds, namely Col II and Col X.

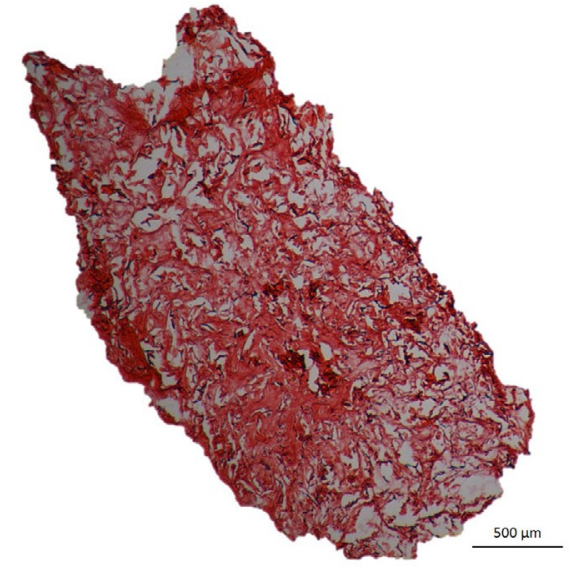

Fig. 7. Demineralised GP scaffold treated with EDTA and cultured in chondrogenic culture conditions for $28 \mathrm{~d}$ stained positively for collagen using picrosirius red staining.

Reviewer II: The use of rat calvaria defects are commonplace for testing bone constructs. However, they do not test the effect of mechanical loading on bone healing and remodelling. Could the authors discuss their decision to use this model with reference to the three Rs?

Authors: Porous scaffold materials such as the ECM scaffold, presented in this publication, would be suitable for non-load bearing maxillofacial applications, or would require the use of a fixation device within a load-bearing site. The rat calvarial defect model is widely used for testing bone regeneration strategies due to its versatility and reproducibility. In our hands, the model also has the benefit of minimal morbidity and periprocedural mortality rates. They are deemed appropriate analogues to the clinical condition they are used to investigate (Spicer et al., 2012).

\section{Additional References}

Dimuzio MT, Veis A (1978) The biosynthesis of phosphophoryns and dentin collagen in the continuously erupting rat incisor. J Biol Chem 253: 6845-6852.

Gerstenfeld LC, Feng M, Gotoh Y, Glimcher MJ (1994) Selective extractability of noncollagenous proteins from chicken bone. Calcif Tissue Int 55: 230-235.

Spicer PP, Kretlow JD, Young S, Jansen JA, Kasper FK, Mikos AG (2012) Evaluation of bone regeneration using the rat critical size calvarial defect. Nat Protoc 7: 1918-1929.

Editor's note: The Scientific Editor responsible for this paper was Chris Evans 